\title{
Glycosidic flavonoids and their potential applications in cancer research: a review
}

\author{
Abuyaseer Abusaliya $^{1}$ - Sang Eun Ha ${ }^{1}$. Pritam Bhagwan Bhosale ${ }^{1} \cdot$ Hun Hwan Kim ${ }^{1}$ Min Yeong Park ${ }^{1}$. \\ Preethi Vetrivel ${ }^{1}$. Gon Sup Kim ${ }^{1}$
}

Accepted: 13 September 2021 / Published online: 22 December 2021

(c) The Author(s) 2021

\begin{abstract}
Purpose of review Every year, the cancer patient registry increases, and the leading cause of death in a global context. Plantbased molecules are gaining attention in cancer research due to the side effects of chemotherapy. A glycosidic derivative of flavonoid (GDF) plays a significant role in cancer proliferation mechanisms. GDF inhibits cell proliferation by elevating the expression of apoptotic proteins, altering the expression of nuclear factor-kappa B (NF- $\kappa B$ ), and decreasing mitochondrial membrane potential $(\Delta \psi \mathrm{m})$ in cancer cells.

Recent findings Reported studies on the flavonoids orientin, vitexin, prunetionoside, chrysin, and scutellarein increased attention and are being widely investigated for their potential role in different parts of cancer research. Prunetionoside is a flavonoid with high cytotoxic potential and capable of inducing necroptosis in AGS gastric cancer cells. Similarly, scutellarein is a flavonol, induces an extrinsic apoptotic pathway and downregulates the expression level of cyclin proteins in HepG2 liver cancer cells. Vitexin is reported to be capable of deregulating the expression levels of p-Akt, p-mTOR, and p-PI3K in A549 lung cancer cells. Orientin inhibits IL-8 expression and invasion in MCF-7 breast cancer cells by suppressing MMP-9 in the presence of TPA via STAT3/AP-1/ERK/PKC $\alpha$-mediated signaling pathways. It also induces mitochondria-mediated intrinsic apoptosis and G0/G1 cell cycle arrest in HT29 colon cancer cells. Chrysin is a flavonoid present in honey that has been shown to play an important role in cervical and colon cancer by suppressing the AKT/mTOR/PI3K pathway and increasing ROS accumulation, LDH leakage, respectively.
\end{abstract}

Keywords Flavonoid $\cdot$ Glycosides $\cdot$ Cancer $\cdot$ Programmed cell death $\cdot$ Cell cycle arrest

\section{Introduction}

Plants are the medicinal hub of the world. Plants or plant extracts are used as a remedy for a variety of human illnesses. Treating disease or illness with medicinal plants is the oldest method by which humanity has cope with illness. The practice of using plants to cure illnesses and diseases was started in the ancient period. Medicinal plants have the ability to cure or prevent diseases. Traditional knowledge plays an important role in medicinal plants and traditional

Preethi Vetrivel

preethivetrive105@gmail.com

Gon Sup Kim

gonskim@gnu.ac.kr

1 Research Institute of Life Science, College of Veterinary Medicine, Gyeongsang National University, Gazwa, Jinju 52828, Republic of Korea healers used a broader range of plants with the potential to cure illness (Khajoei Nasab and Khosravi 2014). At present majority of the drugs were derived from plant sources. The most concerning aspect is that the majority of the plants have not yet been scientifically studied (Phondani et al. 2014). According to a WHO (World Health Organization) report, more than 20,000 plant species are used for medicinal purposes around the globe (Organization 2007).

Medicinal plants have remained as a source of medicine since antiquity and bioactive secondary metabolites contribute to the medicinal properties of herbal drugs (Croteau et al. 2000). For the past two decades, naturally grown medicinal plants have achieved important sources of raw material for traditional medical systems and in analgesics (Bhattacharya et al. 2003). Approximately 85 percent of the source for herbal medicines used in traditional systems of medicine is obtained from medicinal plants (Gustafsson 2002). 
In 2002, WHO reported that the aliment of several illnesses and diseases world's $70 \%$ of the people depend on THCS (Traditional Health Care System). Medicinal plants are the primary source of traditional medicine with more than 3 billion people in less developed countries relying on them and they have been used in herbalism and therapeutics around the globe and they are an important feature of various medicinal systems (Tsabang et al. 2016).

Cancer has become the leading cause of death in recent years, and the global registry of cancer-affected patient rates is growing. The epidemiological data states, about 1,762,450 new cancer registries with 6 lakhs deaths due to cancer in America alone. Similarly, in the South Korean population, cancer is the primary community health concern with agestandardized rates (ASR) of 42.1 and mortality rate (MR) of 8.7 per 100,000 people (Jung et al. 2014) and according to Jung et al., the total new cancer case registry is around 221,347 with 82,344 deaths in Korea (Jung et al. 2019).

\section{Flavonoids on cancer}

Apoptosis or Programmed cell death (PCD) is a key process to uphold homeostasis in the body hence, changes in the process of PCD lead to many disorders including cancer. Apoptosis is usually held by two pathways i.e., Intrinsic and extrinsic pathways which involve the release of cytochrome $\mathrm{C}$ and Fas activation respectively (Reed 2000). For cancer therapeutic strategy, a compound should be able to possess the following abilities, (a) arrest the cell cycle; (b) induce apoptosis; (c) activate Fas Ligand (FasL) and caspases; (d) reduces mitochondrial membrane potential $(\Delta \psi \mathrm{m})$; (e) increase apoptotic protein expressions (Jin and El-Deiry 2005) (Fig. 1).

Naturally, among plant-derived secondary metabolites, flavonoids are the most important metabolites or bio-compounds of medicinal plants with several medicinal values. Studies on herbal extracts have shown that flavonoids have the ability to not only suppress cancer progression but also possess beneficial properties such as anti-diabetic (Zheng, et al. 2011), anti-inflammatory (Clavin et al. 2007), anti-bacterial (Alcaraz et al. 2000), and anti-mutagenic (Miyazawa and Hisama 2003). Studies on cell lines and animal models evidenced that flavonoids have shown activities on cancer suppression, cardioprotective, control diabetes, and treating neurodegenerative disorders (Scalbert et al. 2005). Flavonoids execute the action by either blocking the progression of carcinogenesis or downregulates the proteins for carcinogenesis (Chahar et al. 2011) (Fig. 2).

Flavanoid is a broad group with sub-classes based on the aglycan group which includes, flavonol, flavone, flavanol, isoflavones, flavanone, aurone, and anthocyanin; Structurally, each flavonoid moreover similar and possesses at least two benzene pyran rings with. Among these, flavone and flavonol are the two broad classes of flavonoids (Wang et al. 2018). Some flavone and flavonol are found in various medicinal plants as listed in Table 1.

They have a different mode of biological action and possess executes distant anti-cancer mechanisms in many cancers. Flavonoid glycosides are derived from the flavonoid by the process of glycosylation and as a result, they form $\mathrm{C}$-glycosides or O-glycosides based on the sugar moiety respectively. Excluding hesperidin and rutin, all other flavonoid glycosides possess high solubility in water as well
Fig. 1 Number of scientific papers published annually from 1996 to 2021, search is done through Science Direct on May, 31st 2021

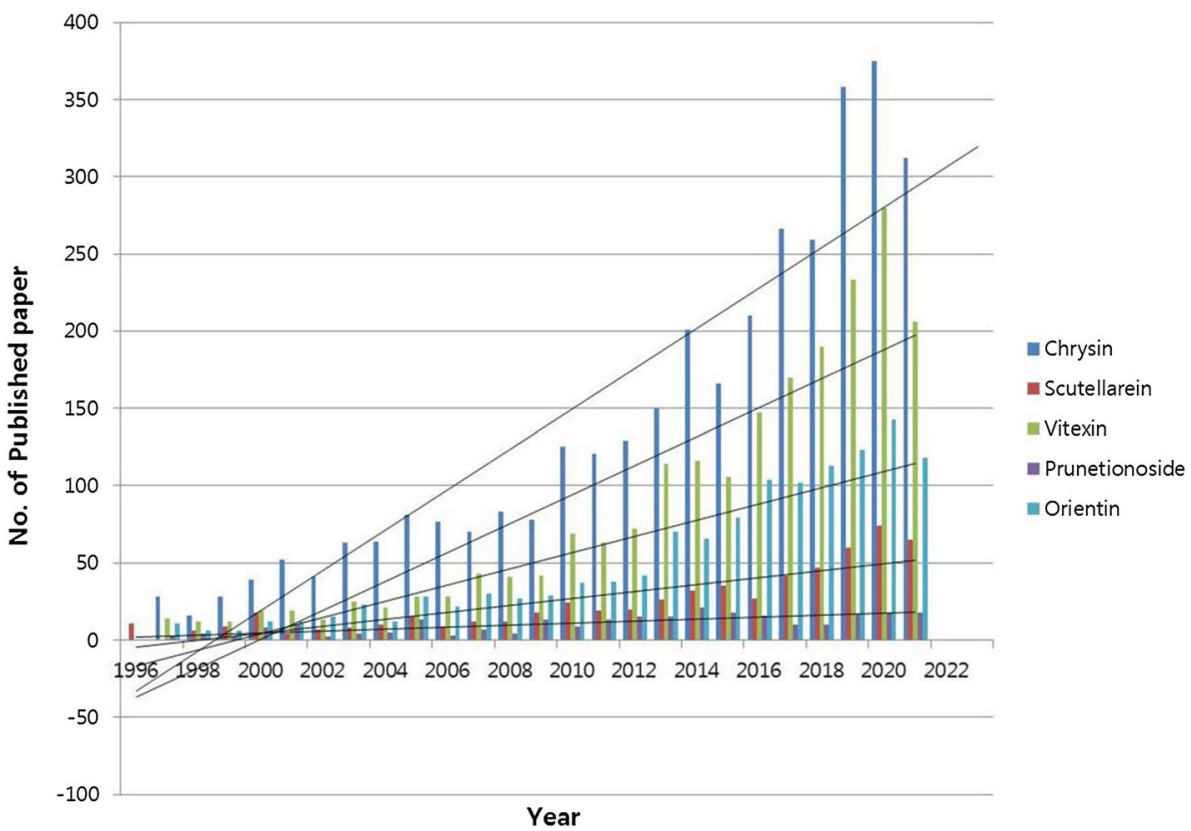


Fig. 2 Different modes of action of glycosidic flavonoids against cancer

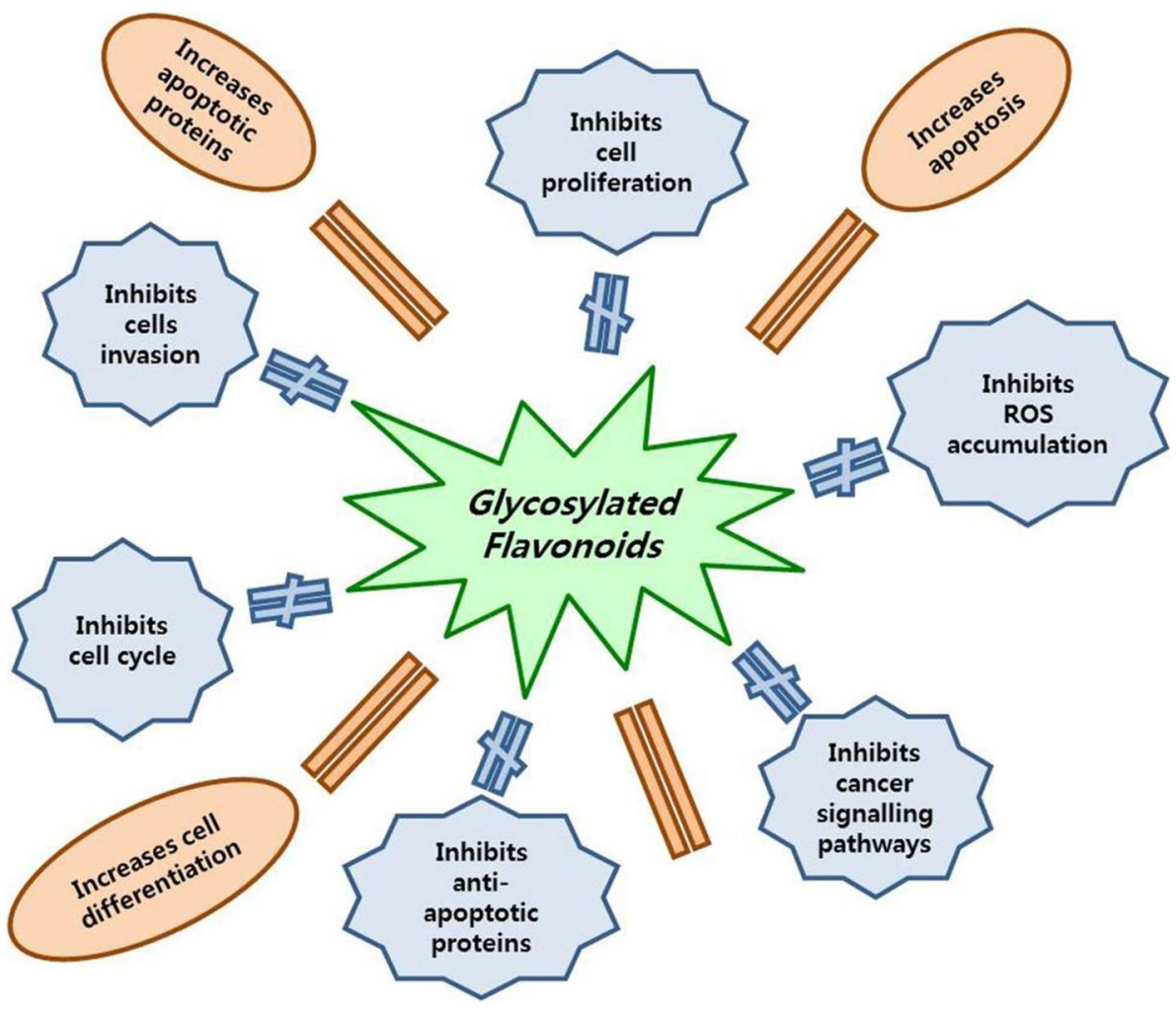

Table 1 List of glycosidic flavonoids reported to be present in medicinal plants

\begin{tabular}{lllll}
\hline Glycoside name & Flavonoid sub-class & Plant species & Plant family & References \\
\hline 5,7-Dihydroxyflavone (chrysin) & Flavone & Calicotome villosa & Leguminosae & Pistelli et al. (2003) \\
5,6,7-Trihydroxyflavone (baicalein) & Flavone & Cephalocereus senilis & Cactaceae & Qin et al. (1993) \\
Baicalein 6-methyl ether (oxoxylin A) & Flavone & Trichosanthes anguina & Cucurbitaceae & Yadava and Syeda (1994) \\
5,7,4'-Trihydroxyflavone (apigenin) & Flavone & Gonocaryum calleryanum & Icacinaceae & Kaneko et al. (1995) \\
Scutellarein 4'-methyl ether 7-Rutinoside & Flavonol & Teucridium parvifolium & Labiatae & Grayer et al. (2002) \\
3,5,7-Trihydroxyflavone (galangin) & Flavonol & Phyllanthus virgatus & Euphorbiaceae Huang et al. (1998) \\
Kaempferol 7-methyl ether (rhamnocitrin) & Flavonol & Cotoneaster simonsii & Rosaceae & Palme et al. (1996) \\
3,5,7,3',4',5'-Hexahydroxyflavone (myricetin) & Flavonol & Davilla flexuosa & Dilleniaceae & David et al. (1996) \\
Apigenin-8-C-glucopyranoside (Vitexin) & Flavone & Crataegus pinnatifida & Rosaceae & An et al. (2015) \\
5,6,7,4'-tetrahydroxyflavone (Scutellarein) & Flavone & Scutellaria & Lamiaceae & Ha et al. (2019) \\
Prunetin 5-O-glucoside (prunetionoside) & Flavonol & Betula sp. & Betulaceae & Vetrivel et al. (2021) \\
\hline
\end{tabular}

as in alcohol (Treml and Šmejkal 2016). Because increased glycosylation increases their structural stability. According to studies, intake of a diet with high dietary flavonoids increases the positive correlation on inflammation and obesity because it is more absorbable in the intestine and thus makes glycosylated flavonoids also to be promising anticancer candidates (Sudhakaran and Doseff 2020).

We have reviewed and brought down the key importance of the glycosidic flavonoid prunetionoside, vitexin, scutellarein, orientin, and chrysin which are constantly studied in the different stages of biological research illustrated in Fig. 1. All five compounds have structural dissimilarity; hold 3 or more phenyl benzo pyrone rings (Fig. 3) and shown effective anti-proliferative activity against cancerous cells by suppressing cell proliferation and by arresting different phases of the cell cycle (Table 2). The selected compounds revealed to have regulates proteins (Table 3 ) and pathways (Table 4) in cancer cell lines. 
A

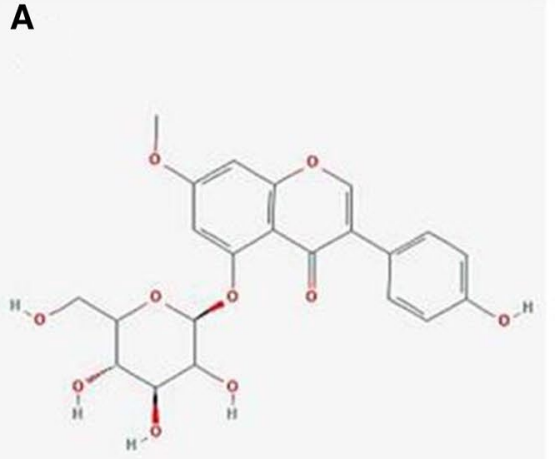

B

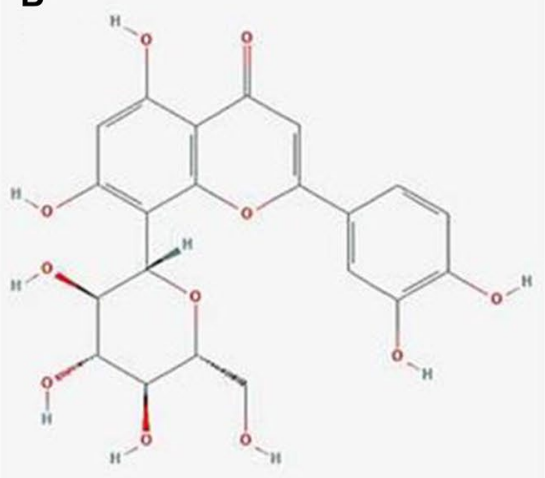

C<smiles>C[C@]1(c2c(O)cc(O)c3c2OC(c2ccc(O)cc2)CC3=O)OC(CO)C(O)C(O)C1O</smiles>

D<smiles>O=C1CC(C2CCC(O)CC2)OC2=C1C(O)C(O)C(O)C2O</smiles>

E<smiles>O=C1CC(c2ccccc2)OC2CC(O)CC(O)C12</smiles>

Fig. 3 Chemical structure of selected glycosidic flavonoids. A Prunetionoside B Orientin C Vitexin D Scutellarein E Chrysin

Table 2 Regulation of cell cycle by glycosidic flavonoids

\begin{tabular}{llll}
\hline Flavonoid & Cell line & Cell cycle regulation & References \\
\hline Vitexin & Human glioblastoma (LN-18) cells & G2/M phase & Yang et al. (2013) \\
Scutellarin & Hepatocellular carcinoma (Hep3B) cells & G2/M phase & Ha et al. (2019) \\
Orientin & Human bladder cancer (T24) cells & G0/G1 phase, S phase & Tian et al. (2019) \\
Chrysin & Human cervical cancer (HeLa) cells & G2/M phase & Raina et al. (2021) \\
Prunetionoside & Human gastric cancer cell (AGS) cells & G1 phase & Vetrivel et al. (2020) \\
\hline
\end{tabular}

\begin{tabular}{lll}
\hline Flavonoid & Suppressed pathway & Activated pathway \\
\hline Prunetionoside & p53 pathway & JNK pathway \\
Vitexin & p42/p44 MAPK pathway & JNK pathway \\
Scutellarin & PI3K/Akt/mTOR signaling pathway & STAT3 pathway, \\
& & HIPPO-YAP pathway \\
Orientin & NF-אB pathway & STAT3 pathway \\
Chrysin & AKT/mTOR/PI3K and MAPK pathway & Akt pathway \\
\hline
\end{tabular}

Table 3 Activation and suppression pathways by glycosidic flavonoids 
Table 4 List of the regulated proteins involved in apoptosis and cell cycle by glycosidic flavonoids

\begin{tabular}{lll}
\hline Flavonoid & Down-regulated proteins & Up-regulated proteins \\
\hline Prunetin & Bax and Rb protein & Bcl2 protein \\
Vitexin & Bal-2, BIRC5, HIF1A and VEGFA & Cleaved caspase-3 \\
Scutellarin & p-Raf, p-MEK1/2, p-ERK1/2, Bcl-XL and Mcl-1 & FasL and cleaved caspase-8, cleaved caspase-3 \\
Orientin & Bcl-2 protein, MMP-9, IL-8, p-Rb, Cyclin E1, and CDK2 & Bax \\
Chrysin & Bcl-xL, Bcl-2, MCL-1, NAIP, and XIAP & $\begin{array}{l}\text { Pro-caspase-3 and Bax pro-apoptotic, Cytochrome C, Bax, p53, } \\
\text { caspase-3, BAD, FAS, FADD, APAF1, BID, caspase-7, caspase-8, } \\
\end{array}$ \\
& & \begin{tabular}{c} 
caspase-9, BOK, FASL, and TNF \\
\hline
\end{tabular}
\end{tabular}

\section{Prunetionoside}

Prunetin 5-O-glucoside also known as prunetionoside, is a flavonoid, derived from Betula sp. and Prunus sp. Previously the crude extract of Betula bark has been reported that it has both in vivo and in vivo anti-inflammatory effect (Kang et al. 2015). A recent study of prunetionoside identified the essential targets on gastric cancer cells to be HSP90, CDK2, and MMP1 with their binding potential confirmed through molecular docking analysis (Vetrivel et al. 2021).

Kooptiwut et al. (2020) reported that prunetin (aglycan form) protected dexamethasone-induced apoptosis of pancreatic cells in rat insulinoma (INS-1) cells through the p53 signaling pathway. Treatment with dexamethasone combined with prunetin considerably reduced $\mathrm{Bax}$ and $\mathrm{Rb}$ protein expressions while it increased the $\mathrm{Bcl} 2$ protein expression (Kooptiwut et al. 2020). Prunetin induced necroptotic cell death in AGS cells via RIPK3 provocation which leads to MLKL-phosphorylation and ROS generation (Vetrivel et al. 2020).

\section{Orientin}

Orientin (luteolin-8-C-glucoside) is a glycosidic derivative of luteolin present widely in Trollius chinensis (Chinese medicinal plant), Ocimum sanctum (holy basil), and Jatropha gossypifolia (bellyache bush). It induces early apoptosis in esophageal cancer cells, inhibits cell growth dose-dependently and time-dependently. It also triggers p53 expression with the down-regulation of $\mathrm{Bcl}-2$ protein (An et al. 2015). Orientin inhibits cell proliferation and induces cell cycle arrest followed by observed apoptotic signaling with increased Bax and decreased Bcl-2 expression. In addition, orientin induces caspase-dependent and mitochondrialdependent apoptotic pathways by the activation of caspase- 3 , caspase-9, and release of cytochrome c in HeLa cells (Guo et al. 2014).

Orientin has shown anti-migratory and anti-invasive properties in TPA-treated MCF-7 breast cancer cells via activation STAT3, ERK, PKC $\alpha$, and AP-1 with the downregulation of MMP-9 and IL-8 expression (Kim et al. 2018). According to a recent study, orientin deregulates $\mathrm{p}-\mathrm{Rb}$ expression and induces ROS generation resulting in the induction of intrinsic apoptosis in human colorectal carcinoma cells (HT29) (Thangaraj et al. 2019). It downregulates PCNA, $\mathrm{Ki} 67$, and inhibits the iNOS, COX-2 expressions in colorectal cancer (CRC) executing both anti-proliferative and anti-inflammatory activities respectively (Thangaraj and Vaiyapuri 2017). In addition, it also protects cellular components from oxidative damage by inducing lipid peroxidation, promoting superoxide dismutase that catalysis $\mathrm{H}_{2} \mathrm{O}_{2}$ to $\mathrm{H}_{2}$ and $\mathrm{O}_{2}$ observed in colorectal cancer (CRC) in rat models (Thangaraj et al. 2018).

A recent report on the T24 cell line showed orientininduced G0-G1 and S phase cell cycle arrest by decreasing the Cyclin E1 and CDK2 expressions. Orientin treatment was also reported to significantly inhibit the NF- $\mathrm{KB}$ signaling pathway and down-regulated the protein expressions of the Hedgehog signaling pathway in human bladder cancer cell lines (Tian et al. 2019).

\section{Vitexin}

Vitexin is apigenin-8-C-glucopyranoside that can be isolated from Desmodium species (Tsai et al. 2011). Vitexin is reported to possess anti-proliferative activities involving the triggering of apoptosis in human leukemia (U937) cells via the mitochondrial death pathway (Lee et al. 2012). Studies have elucidated the potency of vitexin in the suppression of autophagy the induction of apoptosis through the JNK signaling pathway in hepatocellular carcinoma (SK-Hep1 and Hepa1-6) cells (He et al. 2016). Vitexin is also identified to induce $\mathrm{G} 2 / \mathrm{M}$ phase arrest by Akt/mTOR signaling pathway in human glioblastoma (LN-18) cells. Further, activation of p42/p44 MAPK by enhancing the expressions of Bax and p21WAF1 by Vitexin was observed in human oral cancer (OC2) cells. In addition, it also induced apoptosis and metastasis through the p53 signaling pathway and reduces MMP-2 activation by induction of PAI-1 expression in OC2 cells (Yang et al. 2013). 
Recent investigation on non-small cell lung cancer (A549) cells treated with vitexin showed the induction of apoptosis through an intrinsic mitochondrial pathway which was characterized in both in vitro and in vivo models. Collective data showed the decrease of Bal-2 expression and increased cleaved caspase- 3 in tumor tissues. Also, vitexin treatment dose-dependently reduced the protein levels of p-mTOR, p-Akt, and p-PI3K in A549 cells (Liu et al. 2019).

\section{Scutellarein}

Scutellarein (5,6,7,4'-tetrahydroxyflavone) found abundantly in Scutellaria sp. is a bioactive flavone identified with potential activities. It possesses anti-inflammatory, antioxidant, and anti-cancer properties (Xiong et al. 2021). Scutellarein causes up-regulation of FasL and cleaved caspase-8, cleaved caspase-3 with down-regulation of caspase-3, caspase-8 as well as arresting cells at G2/M phase in Hep3B cells (Ha et al. 2019). Scutellarin inhibits cell invasion into bloodstreams; cell migration; and promotes apoptosis in human leukemia (K562) cells (Bao et al. 2020).

In HepG2 cells, it induces apoptosis via the STAT3 pathway by down regulating the anti-apoptotic proteins Bcl-XL and Mcl-1 expression (Xu and Zhang 2013). In addition, ROS generation is a notable sign of cancer, due to mitochondrial error and predominant metabolic activity. Scutellarin decreases the ROS generation in a dose-dependent manner in human liver cancer cells (Xu and Zhang 2013). Scutellarin treatment has pointedly suppressed cell proliferation by induction of both apoptosis and autophagy via the HIPPOYAP signaling pathway in breast carcinoma (MCF-7) cells (Hou et al. 2017).

\section{Chrysin}

Chrysin (5,7-dihydroxyflavone) is a flavonoid glycoside present abundantly in pollens and honey with a wide range of biological activities. It induces apoptosis via dephosphorylation of the Akt signaling pathway by the activation of caspase-3 in human promonocytic (U937) cells (Woo et al. 2004). It has proven to possess the ability to decrease the inflammatory mediators and $\beta$-arrestin with elevated expression of p53 in hepatocarcinoma. Chrysin treatment showed to up-regulate the expression of pro-caspase- 3 and Bax proapoptotic proteins along with down-regulation of $\mathrm{Bcl}-\mathrm{xL}$ expression and it is also evidenced through PCNA staining to be a potential anti-cancer compound (Khan et al. 2011).

Treatment with chrysin increases the expression of the Ten-Eleven Translocation-1 (TET1) enzymes in gastric cancer (MKN45) cells which suppress the invasion and migration effect of cancer cells (Zhong et al. 2021). In human colon cancer (HT-29) cells, it increases the high level of LDH, malondialdehyde leakage, and cell death with high ROS accumulation via up-regulation of cytochrome c, Bax, p53, caspase-3, and caspase- 8 protein levels (Özbolat and Ayna 2020).

A new study using $15 \mu \mathrm{M}$ concentration of chrysin indicates cell cycle arrest at $\mathrm{G} 2 / \mathrm{M}$ phase and downregulates the anti-apoptotic genes including Bcl-2, MCL-1, NAIP, and XIAP while up-regulating BAD, BAX, FAS, FADD, APAF1, BID, caspase-3, caspase-7, caspase-8, and caspase-9, BOK, FASL, and TNF. In the human cervical cancer cell line (HeLa), it suppresses the AKT/mTOR/PI3K and MAPK pathway genes and promotes apoptosis (Raina et al. 2021).

\section{Conclusion and future prospects}

Based on the tumor stage, the method of therapy in cancer is adopted in treatment approaches. Radiation therapy is employed in circumstances of the rapid progressive state, although chemotherapy is considered the most common method that has been used for decades to treat patients. However, due to the increased side effects of synthetic drugs (Lindley et al. 1999) and nonspecific distribution constraints, medicinal plant compounds have provided an alternative remedy for a variety of ailments. Plant metabolite compounds possess a variety of beneficial activities including anti-cancer properties with no negative side effects. Flavonoids could serve as a promising agent for treating cancers by inducing apoptosis, suppressing migration, arresting cell cycle phases, modulating signaling pathways by deregulating the genes involved in it, according to evidence from research studies, some of which are highlighted in this review.

Alarmingly most of the medicinal compounds have no literature and lacks pharmacokinetics research that could be further studied for a better therapeutic strategy. Furthermore, the role of glycosidic flavonoids in cancer and their cancer prevention mechanisms are not well established and more scientific focus is needed. With advanced technologies like Next Generation Sequencing (NGS), transcriptome will reveal molecular level alterations in gene expression concerning flavonoid treatment. Likely, proteomic strategies using nano LC-MS may be applied in flavonoid treated cancer investigations to uncover additional variations of proteins for better knowledge of anti-cancer prospects.

Acknowledgements This study was supported by the National Research Foundation of Korea funded by Ministry of Science and ICT (grant no. 2020R1A2B5B01001807).

Author contributions AA conceptualization, data curation, writingoriginal manuscript, reviewing, and editing; SHE data curation; PBB, 
HHK, MYP formal editing; PV conceptualization, grammar check and co-supervision; GSK conceptualization and supervision.

\section{Declarations}

Conflict of interest Abuyaseer Abusaliya, Preethi Vetrivel, Pritam Bhagwan Bhosale, Sang Eun Ha, Hun Hwan Kim, Min Yeong Park, and Gon Sup Kim declare that they have no conflict of interest.

Human and animal rights This article does not contain any studies with human participants or animals performed by any of the authors.

Open Access This article is licensed under a Creative Commons Attribution 4.0 International License, which permits use, sharing, adaptation, distribution and reproduction in any medium or format, as long as you give appropriate credit to the original author(s) and the source, provide a link to the Creative Commons licence, and indicate if changes were made. The images or other third party material in this article are included in the article's Creative Commons licence, unless indicated otherwise in a credit line to the material. If material is not included in the article's Creative Commons licence and your intended use is not permitted by statutory regulation or exceeds the permitted use, you will need to obtain permission directly from the copyright holder. To view a copy of this licence, visit http://creativecommons.org/licenses/by/4.0/.

\section{References}

Alcaraz LE, Blanco SE, Puig ON, Tomas F, Ferretti FH (2000) Antibacterial activity of flavonoids against methicillin-resistant Staphylococcus aureus strains. J Theor Biol 205:231-240. https://doi.org/10.1006/jtbi.2000.2062

An F, Wang S, Tian Q, Zhu D (2015) Effects of orientin and vitexin from Trollius chinensis on the growth and apoptosis of esophageal cancer EC-109 cells. Oncol Lett 10:2627-2633

Bao J, Xia L, Zhao Y, Xia R (2020) Scutellarin exerts anticancer effects on human leukemia cells via induction of Sub-G1 cell cycle arrest, apoptosis and also inhibits migration and invasion by targeting Raf/MEK/ERK signalling pathway. J BUON 25:1050-1055

Bhattacharya A et al (2003) Highly efficient and selective biocatalytic acylation studies on triazolylsugars. Tetrahedron 59:10269-10277

Chahar MK, Sharma N, Dobhal MP, Joshi YC (2011) Flavonoids: a versatile source of anticancer drugs. Pharmacogn Rev 5:1

Clavin M et al (2007) Anti-inflammatory activity of flavonoids from Eupatorium arnottianum. J Ethnopharmacol 112:585-589. https://doi.org/10.1016/j.jep.2007.04.007

Croteau R, Kutchan TM, Lewis NG (2000) Natural products (secondary metabolites). Biochem Mol Biol Plants 24:1250-1319

David JM, Cruz FG, Guedes MLS, Chávez JP (1996) Flavonol glycosides from Davilla flexuosa. J Braz Chem Soc 7:115-118

Grayer RJ, Veitch NC, Kite GC, Paton AJ, Garnock-Jones PJ (2002) Scutellarein 4'-methyl ether glycosides as taxonomic markers in Teucridium and Tripora (Lamiaceae, Ajugoideae). Phytochemistry 60:727-731

Guo Q et al (2014) Orientin in Trollius chinensis Bunge inhibits proliferation of HeLa human cervical carcinoma cells by induction of apoptosis. Mon Für Chem Chem Mon 145:229-233

Gustafsson L (2002) Presence and abundance of red-listed plant species in Swedish forests. Conserv Biol 16:377-388
Ha SE et al (2019) Scutellarein induces fas-mediated extrinsic apoptosis and G2/M cell cycle arrest in Hep3B hepatocellular carcinoma cells. Nutrients 11:263

He J-D et al (2016) Vitexin suppresses autophagy to induce apoptosis in hepatocellular carcinoma via activation of the JNK signaling pathway. Oncotarget 7:84520

Hou L, Chen L, Fang L (2017) Scutellarin inhibits proliferation, invasion, and tumorigenicity in human breast cancer cells by regulating HIPPO-YAP signaling pathway. Med Sci Monit Int Med J Exp Clin Res 23:5130

Huang Y-L, Chen C-C, Hsu F-L, Chen C-F (1998) Tannins, flavonol sulfonates, and a Norlignan from Phyllanthus Virgatus. J Nat Prod 61:1194-1197

Jin Z, El-Deiry WS (2005) Overview of cell death signaling pathways. Cancer Biol Ther 4:147-171

Jung KW et al (2014) Prediction of cancer incidence and mortality in Korea, 2014. Cancer Res Treat 46:124-130. https://doi.org/10. 4143/crt.2014.46.2.124

Jung KW, Won YJ, Kong HJ, Lee ES (2019) Prediction of cancer incidence and mortality in Korea, 2019. Cancer Res Treat 51:431437. https://doi.org/10.4143/crt.2019.139

Kaneko T et al (1995) Secoiridoid and flavonoid glycosides from Gonocaryum calleryanum. Phytochemistry 39:115-120

Kang H, Kwak T-K, Kim B-G, Lee K-J (2015) The anti-inflammatory effect of Prunus yedoensis bark extract on adipose tissue in dietinduced obese mice. Evid Based Complement Altern Med. https:// doi.org/10.1155/2015/937904

Khajoei Nasab F, Khosravi AR (2014) Ethnobotanical study of medicinal plants of Sirjan in Kerman Province Iran. J Ethnopharmacol 154:190-197. https://doi.org/10.1016/j.jep.2014.04.003

Khan MS, Devaraj H, Devaraj N (2011) Chrysin abrogates early hepatocarcinogenesis and induces apoptosis in $\mathrm{N}$-nitrosodiethylamineinduced preneoplastic nodules in rats. Toxicol Appl Pharmacol 251:85-94

Kim S-J et al (2018) Orientin inhibits invasion by suppressing MMP-9 and IL- 8 expression via the PKC $\alpha /$ ERK/AP-1/STAT3-mediated signaling pathways in TPA-treated MCF-7 breast cancer cells. Phytomedicine 50:35-42

Kooptiwut S, Samon K, Semprasert N, Suksri K, Yenchitsomanus P-T (2020) Prunetin protects against dexamethasone-induced pancreatic B-cell apoptosis via modulation of p53 signaling pathway. Nat Product Commun 15:1934578X20916328

Lee C-Y et al (2012) Apoptosis triggered by vitexin in U937 human leukemia cells via a mitochondrial signaling pathway. Oncol Rep 28:1883-1888

Lindley C et al (1999) Perception of chemotherapy side effects cancer versus noncancer patients. Cancer Pract 7:59-65

Liu X, Jiang Q, Liu H, Luo S (2019) Vitexin induces apoptosis through mitochondrial pathway and PI3K/Akt/mTOR signaling in human non-small cell lung cancer A549 cells. Biol Res 52:1-7

Miyazawa M, Hisama M (2003) Antimutagenic activity of flavonoids from Chrysanthemum morifolium. Biosci Biotechnol Biochem 67:2091-2099. https://doi.org/10.1271/bbb.67.2091

Özbolat SN, Ayna A (2020) Chrysin suppresses HT-29 cell death induced by diclofenac through apoptosis and oxidative damage. Nutr Cancer 73:1-10

Palme E, Bilia AR, Morelli I (1996) Flavonols and isoflavones from Cotoneaster simonsii. Phytochemistry 42:903-905

Phondani PC, Maikhuri RK, Saxena KG (2014) The efficacy of herbal system of medicine in the context of allopathic system in Indian Central Himalaya. J Herb Med 4:147-158

Pistelli L, Fiumi C, Morelli I, Giachi I (2003) Flavonoids from Calicotome villosa. Fitoterapia 74:417-419

Qin L, Dixon RA, Mabry TJ (1993) Additional flavonoids from elicitor-treated cell cultures of Cephalocereus senilis. Phytochemistry $34: 167-170$ 
Raina R et al (2021) Chrysin inhibits propagation of HeLa cells by attenuating cell survival and inducing apoptotic pathways. Eur Rev Med Pharmacol Sci 25:2206-2220

Reed JC (2000) Mechanisms of apoptosis. Am J Pathol 157:1415-1430

Scalbert A, Manach C, Morand C, Rémésy C, Jiménez L (2005) Dietary polyphenols and the prevention of diseases. Crit Rev Food Sci Nutr 45:287-306

Sudhakaran M, Doseff AI (2020) The targeted impact of flavones on obesity-induced inflammation and the potential synergistic role in cancer and the gut microbiota. Molecules 25:2477

Thangaraj K, Vaiyapuri M (2017) Orientin, a C-glycosyl dietary flavone, suppresses colonic cell proliferation and mitigates $\mathrm{NF}-\kappa \mathrm{B}$ mediated inflammatory response in 1, 2-dimethylhydrazine induced colorectal carcinogenesis. Biomed Pharmacother 96:1253-1266

Thangaraj K et al (2018) Orientin mitigates 1, 2-dimethylhydrazine induced lipid peroxidation, antioxidant and biotransforming bacterial enzyme alterations in experimental rats. J Cancer Res Ther 14:1379

Thangaraj K et al (2019) Orientin induces G0/G1 cell cycle arrest and mitochondria mediated intrinsic apoptosis in human colorectal carcinoma HT29 cells. Biomolecules 9:418

Tian F et al (2019) The effects of orientin on proliferation and apoptosis of T24 human bladder carcinoma cells occurs through the inhibition of nuclear factor-kappaB and the hedgehog signaling pathway. Med Sci Monit Int Med J Exp Clin Res 25:9547

Treml J, Šmejkal K (2016) Flavonoids as potent scavengers of hydroxyl radicals. Compr Rev Food Sci Food Saf 15:720-738

Tsabang N, Ngah N, Estella FT, Agbor G (2016) Herbal medicine and treatment of diabetes in Africa: case study in Cameroon. Diabetes Case Rep 1:2

Tsai J-C et al (2011) Antioxidant activities of phenolic components from various plants of Desmodium species. Afr J Pharm Pharmacol 5:468-476

Vetrivel P et al (2020) Compound prunetin induces cell death in gastric cancer cell with potent anti-proliferative properties: in vitro assay, molecular docking, dynamics, and ADMET studies. Biomolecules 10:1086

Vetrivel P et al (2021) A Network pharmacological approach to reveal the pharmacological targets and its associated biological mechanisms of prunetin-5-O-glucoside against gastric cancer. Cancers 13:1918

Wang T-Y, Li Q, Bi K-S (2018) Bioactive flavonoids in medicinal plants: Structure, activity and biological fate. Asian J Pharm Sci 13:12-23

Woo KJ, Jeong Y-J, Park J-W, Kwon TK (2004) Chrysin-induced apoptosis is mediated through caspase activation and Akt inactivation in U937 leukemia cells. Biochem Biophys Res Commun 325:1215-1222

World Health Organization (2007) Quality assurance of pharmaceuticals: a compendium of guidelines and related materials. Good manufacturing practices and inspection, vol 2. World Health Organization, Geneva

Xiong L-L et al (2021) Effect of Sutellarin on neurogenesis in neonatal hypoxia-ischemia rat model: potential mechanisms of action. Am J Chin Med 49:677-703

$\mathrm{Xu} \mathrm{H}$, Zhang S (2013) Scutellarin-induced apoptosis in HepG2 hepatocellular carcinoma cells via a STAT3 pathway. Phytother Res 27:1524-1528

Yadava R, Syeda Y (1994) A novel flavone glycoside from Trichosanthes anguina seeds. Fitoterapia (Milano) 65:6

Yang SH et al (2013) The novel p53-dependent metastatic and apoptotic pathway induced by vitexin in human oral cancer OC 2 cells. Phytother Res 27:1154-1161

Zheng XK et al (2011) Anti-diabetic activity and potential mechanism of total flavonoids of Selaginella tamariscina (Beauv.) spring in rats induced by high fat diet and low dose STZ. J Ethnopharmacol 137:662-668. https://doi.org/10.1016/j.jep.2011.06.018

Zhong X et al (2021) Chrysin induced cell apoptosis and inhibited invasion through regulation of TET1 expression in gastric cancer cells [corrigendum]. OncoTargets Ther 14:697-698

Publisher's Note Springer Nature remains neutral with regard to jurisdictional claims in published maps and institutional affiliations. 